\title{
Major Histocompatibility Complex Class I Molecule Expression Is Normal on Peripheral Blood Lymphocytes from Patients with Insulin-dependent Diabetes Mellitus
}

\author{
Wei Hao, ${ }^{\star \ddagger}$ Paul Gladstone,${ }^{\S}$ Susan Engardt, ${ }^{\S}$ Carla Greenbaum, ${ }^{\star \ddagger}$ and Jerry P. Palmer ${ }^{\star \ddagger}$ \\ $*$ Department of Veterans Affairs Puget Sound Health Care System, Seattle, Washington 98108; ${ }^{\ddagger}$ Department of Medicine, University of \\ Washington, Seattle, Washington 98195; and ${ }^{\S}$ Bristol-Myers Squibb Pharmaceutical Research Institute, Seattle, Washington 98121
}

\begin{abstract}
Recent work from one laboratory has shown, in both nonobese diabetic mice and humans, an association between insulin-dependent diabetes mellitus (IDDM) and quantitative difference in MHC class I molecule expression. This reported decrease in MHC class I molecule expression is very controversial in the nonobese diabetic mouse model of IDDM, but to our knowledge, it has not been evaluated by another group in human IDDM. To evaluate this question, we studied 30 patients with IDDM and 30 age- and sexmatched normal controls. MHC class I molecule expression was measured by flow cytometry with conformationaldependent MHC class I mAbs. The mean antigen density of MHC class I molecule expression in IDDM vs. normal control is $454 \pm 34$ vs. $440 \pm 28$ for lymphocytes and $1,440 \pm 117$ vs. $1,494 \pm 117$ for monocytes, both $P>0.05$. Three conformational-dependent MHC class I antibodies showed consistent results. To estimate the biological variation of MHC class I molecule expression in normal controls, we also studied 10 age- and sex-matched normal control pairs. Using $\overline{\mathrm{X}} \pm \mathrm{SD}$ of the percentage difference of mean antigen density in the normal control pairs as our definition of normal, we found that $70 \%(21 / 30)$ of IDDM patients had normal, $13 \%$ (4/30) of IDDM patients had decreased, and $17 \%(5 / 30)$ of IDDM patients had increased MHC class I molecule expression on lymphocytes. All IDDM patients showed normal MHC class I expression on monocytes. In conclusion, we find that there is no consistent decrease in MHC class I molecule expression on either lymphocytes or monocytes from patients with IDDM. The MHC class I molecule expression observed in IDDM patients is largely within the expected biological variation of MHC class I molecule expression that has been observed in normal controls. ( J. Clin. Invest. 1996. 98:1613-1618.) Key words: major histocompatibility complex class I • insulin-dependent diabetes mellitus • lymphocytes
\end{abstract}

\section{Introduction}

MHC class I molecules contain two separate polypeptide chains: an MHC-encoded $\alpha$ or heavy chain, and a non-MHC

Address correspondence to Wei Hao, M.D., DVA Puget Sound Health Care System, Endocrinology (111), 1660 South Columbian Way, Seattle, WA 98108. Phone: 206-764-2774; FAX: 206-764-2693; E-mail:weihao@u.washington.edu

Received for publication 10 May 1996 and accepted in revised form 23 July 1996.

The Journal of Clinical Investigation

Volume 98, Number 7, October 1996, 1613-1618 encoded $\beta$ chain. In humans, the $\alpha$ chain is a $44-\mathrm{kD}$ transmembrane glycoprotein, and the $\beta$ chain is a nonpolymorphic $12-\mathrm{kD}$ polypeptide ( $\beta 2$ microglobulin). The $\beta$ chain interacts noncovalently with the $\alpha$ chain. The association of the $\alpha$ chain with the $\beta$ chain occurs intracellularly within the endoplasmic reticulum and appears to be critical for maintaining MHC class I molecules in their original conformation $(1,2)$. The surface expression of MHC class I molecules is also dependent on the binding to the peptides that are being processed within the cell. Association of such peptides with the MHC class I peptide-binding cleft promotes association of the $\alpha$ chain with $\beta$ chain and correct folding of the complete MHC class I molecules, thus maintaining the conformational stability of $\mathrm{MHC}$ class I molecules $(1,2)$.

Antigen-processing (TAP $)^{1}$ genes encode peptide transporters that carry peptides (derived from self or viral peptides) from the cytoplasm into the endoplasmic reticulum, where the peptides complex with the MHC class I molecules. This trimolecular complex of $\alpha$ chain, $\beta$ chain, and peptides is conformationally stable and is expressed on the cell surface (3-7).

The principal function of MHC class I molecules is to present endogenous antigens (peptides) to $\mathrm{CD}^{+} \mathrm{T}$ lymphocytes. The expression and presentation of MHC class I molecules is necessary for establishing self-tolerance, and decreased expression of such molecules has been hypothesized to lead to autoimmune diseases secondary to impaired self-tolerance. Decreased expression of MHC class I molecules on lymphocytes from patients with insulin-dependent diabetes mellitus (IDDM) and nonobese diabetic (NOD) mice, an animal model of autoimmune diabetes, has been reported $(8,9)$. Mutation and defective expression of TAP-1 has been reported to result in decreased MHC class I molecule expression in NOD mice $(8,9)$. Since the TAP gene is located within the class II locus, the TAP gene is a candidate MHC class II-related diabetes susceptibility gene in the NOD mice $(8,9)$. In addition, decreased MHC class I molecule expression has been reported with other autoimmune diseases (10). Other groups, however, have reported no decreased expression of MHC class I molecules on lymphocytes from NOD mice (11-13). To evaluate this question in human IDDM, we made a careful study of the MHC class I molecule expression on PBLs from patients with IDDM.

\section{Methods}

We studied 30 patients with IDDM (mean age $=32.57 \pm 6.15 \mathrm{yr}$; female/male ratio $(\mathrm{F} / \mathrm{M})=13 / 17)$, which include 12 recent onset $(<2.5$

1. Abbreviations used in this paper: $\mathrm{F} / \mathrm{M}$, female/male ratio; IDDM, insulin-dependent diabetes mellitus; NOD, nonobese diabetic mouse; TAP gene, transporter associated with antigen-processing gene. 
yr) $\operatorname{IDDM}($ duration $=11.46 \pm 7.27 \mathrm{mo}$, age $=28.25 \pm 5.74 \mathrm{yr}, \mathrm{F} / \mathrm{M}=$ 4/8), 18 long duration $(>10 \mathrm{yr}$ ) IDDM (duration $=21.28 \pm 6.90 \mathrm{yr}$, age $=35.44 \pm 4.62 \mathrm{yr}, \mathrm{F} / \mathrm{M}=9 / 9), 30$ age- and sex-matched normal controls (age $=30.50 \pm 7.05 \mathrm{yr}, \mathrm{F} / \mathrm{M}=13 / 17)$ without a family history of IDDM or other autoimmune diseases (Table I).

MHC class I molecule expression was measured by flow cytometry using the methods described by Faustman et al. $(8,10)$. PBL were prepared from anticoagulant-treated blood by Ficoll-Hypaque gradient separation. $10^{6}$ freshly isolated PBLs were stained with MHC class I mAb W6/32 at a final concentration of $1.5 \mu \mathrm{g} / \mathrm{ml}$ in $100 \mu \mathrm{l}$ RPMI 1640 medium containing 2\% FBS for $15 \mathrm{~min}$ at room temperature. $\mathrm{mAb} \mathrm{W} 6 / 32$ is a conformational-dependent antibody that reacts preferentially with peptide-occupied MHC class I molecules and recognizes all alleles of human MHC class I molecules. The mAb W6/32 used in this study was kindly provided by Dr. Faustman (Immunology Laboratory, Harvard Medical School, Cambridge, MA), and the concentration of the antibody used in this study was identical to the concentration used by Faustman et al. $(8,10)$. This low concentration of W6/32 has been previously demonstrated to maximize the measurement of conformational-dependent (peptide-occupied) MHC class I molecules (10). After washing, the cells were incubated with goat anti-mouse IgG2a-FITC-conjugated secondary antibody (1:50; Southern Biotechnology Associates, Inc., Birmingham, AL) for $15 \mathrm{~min}$ at room temperature in the dark and followed by washing. Flow cytom-

\section{Table I. Clinical Information on Patients with IDDM}

\begin{tabular}{|c|c|c|c|c|c|}
\hline Subject number & Age & Sex & Duration & Age at diagnosis & $\begin{array}{c}\text { Islet } \\
\text { Cell } \\
\text { Antibody }\end{array}$ \\
\hline & $y r$ & & yror mo & $y r$ & \\
\hline 1 & 33 & $\mathrm{~F}$ & $12 y$ & 11 & + \\
\hline 2 & 23 & $\mathrm{~F}$ & $15 y$ & 8 & + \\
\hline 3 & 36 & $\mathrm{~F}$ & $28 y$ & 8 & NT \\
\hline 4 & 39 & $\mathrm{~F}$ & $28 y$ & 11 & NT \\
\hline 5 & 31 & $\mathrm{~F}$ & $23 y$ & 8 & NT \\
\hline 6 & 40 & $\mathrm{~F}$ & $22 y$ & 18 & - \\
\hline 7 & 39 & $\mathrm{~F}$ & $26 y$ & 13 & - \\
\hline 8 & 35 & $\mathrm{M}$ & $18 y$ & 17 & + \\
\hline 9 & 38 & $\mathrm{~F}$ & $13 y$ & 25 & - \\
\hline 10 & 26 & $\mathrm{~F}$ & $16 y$ & 10 & - \\
\hline 11 & 29 & $\mathrm{M}$ & $20 y$ & 9 & - \\
\hline 12 & 34 & $\mathrm{M}$ & $24 y$ & 10 & - \\
\hline 13 & 28 & $\mathrm{M}$ & $11 \mathrm{~m}$ & 27 & - \\
\hline 14 & 38 & $\mathrm{M}$ & $13 y$ & 25 & - \\
\hline 15 & 28 & $\mathrm{M}$ & $15 \mathrm{~m}$ & 27 & + \\
\hline 16 & 36 & $\mathrm{M}$ & $22 y$ & 14 & + \\
\hline 17 & 41 & $\mathrm{~F}$ & $14 \mathrm{~m}$ & 39 & + \\
\hline 18 & 25 & $\mathrm{~F}$ & $11 \mathrm{~m}$ & 24 & + \\
\hline 19 & 24 & $\mathrm{M}$ & $7 \mathrm{~m}$ & 23 & + \\
\hline 20 & 37 & $\mathrm{M}$ & $31 y$ & 6 & + \\
\hline 21 & 34 & $\mathrm{M}$ & $27 \mathrm{~m}$ & 32 & - \\
\hline 22 & 22 & $\mathrm{M}$ & $0.5 \mathrm{~m}$ & 22 & - \\
\hline 23 & 30 & $\mathrm{~F}$ & $12 \mathrm{~m}$ & 29 & - \\
\hline 24 & 33 & $\mathrm{M}$ & $16 \mathrm{~m}$ & 32 & + \\
\hline 25 & 26 & $\mathrm{~F}$ & $17 \mathrm{~m}$ & 24 & + \\
\hline 26 & 41 & $\mathrm{M}$ & $37 y$ & 4 & + \\
\hline 27 & 36 & $\mathrm{M}$ & $20 y$ & 16 & - \\
\hline 28 & 43 & $\mathrm{M}$ & $15 y$ & 28 & + \\
\hline 29 & 28 & $\mathrm{M}$ & $11 \mathrm{~m}$ & 27 & - \\
\hline 30 & 20 & $\mathrm{M}$ & $7 \mathrm{~m}$ & 19 & + \\
\hline
\end{tabular}

$I C A$, islet cell antibody, $N T$, not tested. etry analysis was then performed immediately. Mean antigen density was measured by a FACScan ${ }^{\circledR}$ (Becton Dickinson \& Co., Mountain View, CA). Two gates were set up on the FACScan ${ }^{\circledR}$ by size to distinguish between lymphocytes and monocytes. The setting of the lymphocyte and monocyte gates was demonstrated to be efficient by two-color staining using the monocyte marker CD14-PE-conjugated antibody (Becton Dickinson). In the monocyte gate, $>95 \%$ of cells were positive for the monocyte marker; in the lymphocyte gate, there was $<2 \%$ of cells that were positive for the monocyte marker. 50,000 cells were assayed in each sample.

We studied individual sex- and age-matched IDDM and normal controls on the same day to allow direct comparison of the IDDM patient and control. The FACScan ${ }^{\circledR}$ measurement was performed within 2-3 h after blood withdrawal. This procedure was followed to prevent low temperature from correcting defective MHC class I molecule expression in vitro (9). Two different anticoagulants (heparin

A



B



C

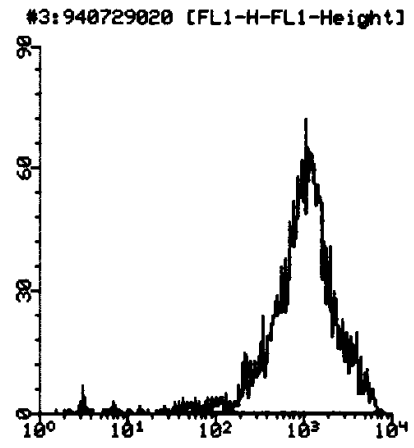

Fluorescence Intensity $(\log )$

Figure 1. Expression of MHC class I molecule on cell lines. $(A)$ The cell line with missing MHC class I transporter \& a mutation in MHC class II (5.2.4). (B) The cell line with mutation in MHC class II (9.5.3). (C) The cell line with normal MHC class I molecule (COX). 

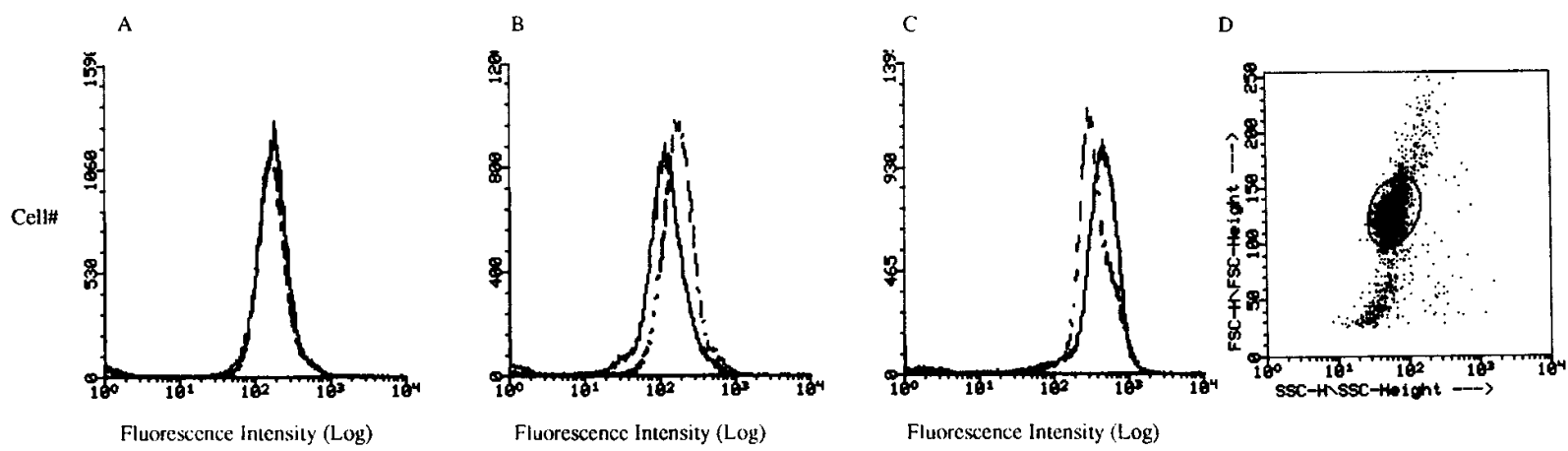

Figure 2. Patterns of MHC class I expression on lymphocytes from IDDM patients compared with the matched normal controls. Solid line peak, IDDM; dash line peak, normal control. The IDDM patient showed $(A)$ similar, $(B)$ decreased, and $(C)$ increased MHC class I molecule expression vs the control. $(D)$ The gate of lymphocytes selected on FACScan ${ }^{\circledR}$.

and acid citric dextrose) were tested to determine the potential effect on results.

We also studied 12 IDDM patients and matched controls with other MHC class I mAbs: HIDE and P10.1. These are also conformational-dependent antibodies that react with peptide-occupied MHC class I molecules and recognize all alleles of human MHC class I molecules (14). The mAbs HIDE and P10.1 were provided by BristolMyers Squibb Pharmaceutical Research Institute (Seattle, WA). In addition, we studied 10 age- and sex-matched normal control pairs (age $=28.05 \pm 5.56 \mathrm{yr}, \mathrm{F} / \mathrm{M}=4 / 6)$ with $\mathrm{mAb} \mathrm{W} 6 / 32$ to determine the variation of MHC class I molecule expression that would be expected in normal controls studied together on the same day.

A cell line with missing MHC class I transporter and a mutation in the MHC class II diabetes mellitus allele (5.2.4) was used as a positive control. A cell line with a mutation only in the MHC class II diabetes mellitus allele (9.5.3) and a cell line with normal expression of MHC class I molecules (COX) were used as negative controls. The mutant cell lines 5.2.4 and 9.5.3 were derived from a human B-lymphoblastoid cell line (15) and were kindly provided by Drs. Pious and Mellins (Departments of Pediatrics, Immunology and Genetics, University of Washington, Seattle, WA).

Statistical analysis. Results are shown as mean \pm SEM. The Student's $t$ test was used to compare the mean antigen density of MHC class I molecule expression between IDDM patients and normal controls, and statistical significance is defined as $<0.05$.

\section{Results}

Using mAb W6/32, the cell line 5.2.4 with the missing MHC class I transporter showed dramatically decreased fluorescence

Table II. MHC Class I Molecule Expression on Lymphocytes from IDDM Patients Compared with the Matched Normal Controls (Visual Inspection)

\begin{tabular}{lccc}
\hline & \multicolumn{3}{c}{ MHC class I molecule expression } \\
\cline { 2 - 4 } & $\begin{array}{c}\text { Similar } \\
n(\%)\end{array}$ & $\begin{array}{c}\text { Decreased } \\
n(\%)\end{array}$ & $\begin{array}{c}\text { Increased } \\
n(\%)\end{array}$ \\
\hline $\begin{array}{l}\text { New-onset IDDM } \\
(n=12)\end{array}$ & 2 & 3 & 7 \\
$\begin{array}{l}\text { Long-duration IDDM } \\
(n=18)\end{array}$ & 6 & 3 & 9 \\
Total $(n=30)$ & $8(27 \%)$ & $6(20 \%)$ & $16(53 \%)$ \\
\hline
\end{tabular}

intensity (the peak of fluorescence intensity shifts to left) compared with the cell line 9.5.3 with mutation only in MHC class II DM allele and the cell line COX with normal expression of MHC class I molecules (Fig. 1).

Using only visual inspection of the results, we find that there are three patterns of MHC class I molecule expression (similar, decreased, and increased) on lymphocytes from patients with IDDM compared with age- and sex-matched controls (Fig. 2). Analyzed in this manner, 27\% (8/30) of IDDM patients showed similar, 20\% (6/30) showed decreased, and $53 \%$ (16/30) showed increased MHC class I molecule expression on lymphocytes compared with the matched controls. This pattern of MHC class I molecule expression was observed in both recent onset IDDM and long-duration IDDM patients (Table II). MHC class I molecule expression on monocytes showed a similar pattern (Table III). In addition, there was no difference in the mean antigen density of MHC class I molecule expression on either lymphocytes or monocytes between IDDM patients and normal controls (mean antigen density of IDDM vs. normal control ( $X \pm \mathrm{SEM})$ : $454 \pm 34$ vs. $440 \pm 28$ for lymphocytes and $1,440 \pm 117$ vs. $1,494 \pm 117$ for monocytes, both $P>0.05)$.

To determine the normal variation of MHC class I molecule expression in normal controls using this methodology, we studied 10 sex- and age-matched normal control pairs as if they were a matched pair consisting of an IDDM patient and a control. The mAb W6/32 was used. As shown in Table IV, $\overline{\mathrm{X}} \pm \mathrm{SD}$ of the percentage difference of mean antigen density of $\mathrm{MHC}$

Table III. MHC Class I Molecule Expression on Monocytes from IDDM Patients Compared with the Matched Normal Controls (Visual Inspection)

\begin{tabular}{lccc}
\hline & \multicolumn{3}{c}{ MHC class I molecule expression } \\
\cline { 2 - 4 } & $\begin{array}{c}\text { Similar } \\
n(\%)\end{array}$ & $\begin{array}{c}\text { Decreased } \\
n(\%)\end{array}$ & $\begin{array}{c}\text { Increased } \\
n(\%)\end{array}$ \\
\hline $\begin{array}{l}\text { New-onset IDDM } \\
(n=12)\end{array}$ & 2 & 6 & 4 \\
$\begin{array}{l}\text { Long-duration IDDM } \\
(n=18)\end{array}$ & 6 & 6 & 6 \\
Total $(n=30)$ & $8(27 \%)$ & $12(40 \%)$ & $10(33 \%)$
\end{tabular}


Table IV. The Percentage Difference of Mean Antigen Density of MHC Class I Molecule Expression on Lymphocytes and Monocytes in Normal Control Pairs

\begin{tabular}{lcc}
\hline Pair number & Lymphocytes & Monocytes \\
\hline 1 & $-8.6 \%$ & $61.4 \%$ \\
2 & $-14.9 \%$ & $-14.3 \%$ \\
3 & $6.4 \%$ & $-21.1 \%$ \\
4 & $16.2 \%$ & $44.2 \%$ \\
5 & $-10.7 \%$ & $0.3 \%$ \\
6 & $21.9 \%$ & $-15.9 \%$ \\
7 & $10.6 \%$ & $25.9 \%$ \\
8 & $8.2 \%$ & $41.3 \%$ \\
9 & $0.4 \%$ & $-32.2 \%$ \\
10 & $6.3 \%$ & $15.8 \%$ \\
$\mathrm{X} \pm \mathrm{SD}$ & $3.58 \pm 11.9(\%)$ & $10.54 \pm 31.9(\%)$ \\
& &
\end{tabular}

The percentage difference was calculated by the difference of mean antigen density between the two matched control (NC1-NC2) divided by mean antigen density of $\mathrm{NC} 2 \times 100$. A minus difference means that the NC1 has decreased MHC class I molecule expression compared with NC2.

class I molecule expression from these normal control pairs is $3.58 \pm 11.9(\%)$ on lymphocytes and $10.54 \pm 31.9$ ( \%) on monocytes. The $\overline{\mathrm{X}} \pm 2 \mathrm{SD}$ of the percentage difference of mean antigen density from the normal control pairs was defined as normal. Using this definition of normal, we determined the frequency of IDDM patients with normal, decreased, and increased MHC class I molecule expression: $70 \%(21 / 30)$ of IDDM patients were normal, 13\% (4/30) of IDDM patients had decreased, and $17 \%(5 / 30)$ of IDDM patients had increased MHC class I molecule expression on lymphocytes (Fig. 3). All IDDM patients showed normal MHC class I molecule expression on monocytes.

In addition, we studied 12 IDDM patients and their matched normal controls with other conformational-dependent MHC class I mAbs: HIDE and P10.1. When compared to antibody W6/32, consistent results were obtained in each individual pair (Table V).

\section{Discussion}

Faustman et al. originally reported decreased expression of MHC class I molecules on lymphocytes from human IDDM and NOD mice $(8,9)$. This decreased expression of MHC class I molecules on the surface of PBLs was predictive of the progression to hyperglycemia in genetically susceptible populations of both humans and mice (8). A mutation of TAP-1 has also been reported to contribute to this decreased MHC class I molecule expression $(8,9)$. Furthermore, T cells from IDDM patients were reported to have decreased activation and proliferation response to self-antigen presented by autologous cells in autologous mixed lymphocyte reaction (8). Therefore, Faustman et al. concluded that deficient surface expression of peptide-occupied MHC class I molecules is closely associated with autoimmune diabetes. They proposed that the defect in antigen presentation may impair the development of self-tolerance leading to autoimmunity. Further study by this group reported decreased MHC class I molecule expression on lymphocytes in other autoimmune diseases (10), and they concluded that autoimmune diseases are characterized by de-

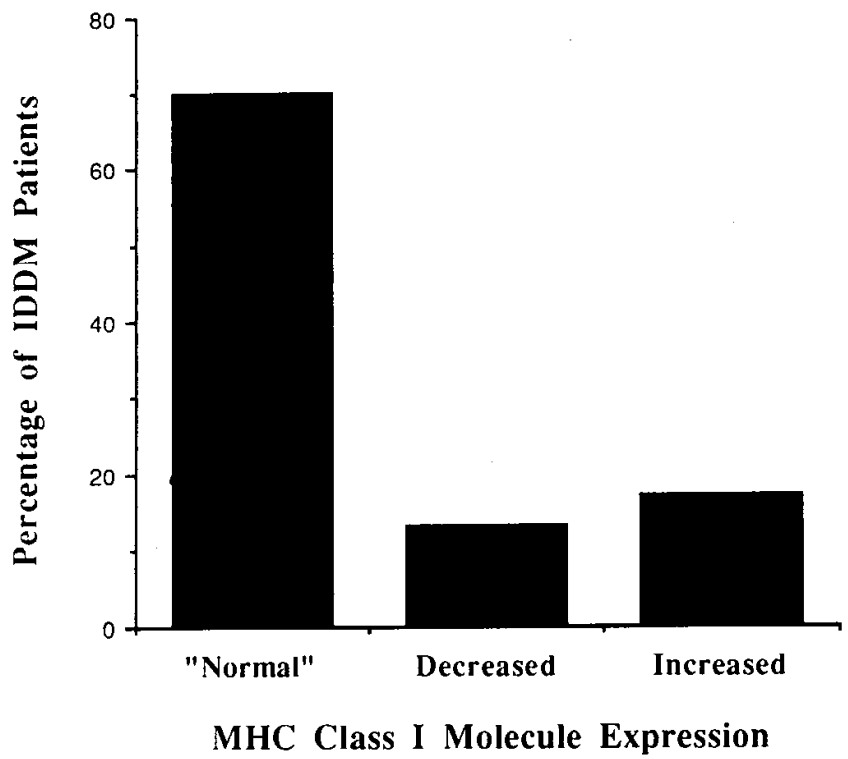

Figure 3. The frequency of IDDM patients with normal, decreased, and increased MHC class I molecule expression on lymphocytes.

creased expression of MHC class I on lymphocytes. More recently, this group reported that in NOD mice, there was an abnormal assembly and peptide presentation, and reestablishment of endogenous MHC class I and self-peptide presentation by CFA and mouse hepatitis virus restored MHC class I molecule expression, increased TAP-1 mRNA abundance, eliminated in vitro autoreactivity to self-MHC class I in autologous mixed lymphocyte reactions, and prevented diabetes in NOD mice $(16,17)$. Others have reported, however, that TAP-1 and MHC class I molecule expression are normal in NOD mice. Gaskins et al. specifically addressed the question

Table V. The Percentage Difference of Mean Antigen Density of MHC Class I Molecule Expression with Multiple Conformational-dependent MHC Class I Antibodies in IDDM Patients Compared with the Matched Normal Controls

\begin{tabular}{cccc}
\hline Pair number & HIDE & P10.1 & W6/32 \\
\hline 1 IDDM vs NC & $-24.6 \%$ & $-59.2 \%$ & NT \\
2 IDDM vs NC & $-19.1 \%$ & $-45.3 \%$ & NT \\
3 IDDM vs NC & $16.2 \%$ & $85.4 \%$ & NT \\
4 IDDM vs NC & $24.4 \%$ & $17.9 \%$ & NT \\
5 IDDM vs NC & $11.5 \%$ & $21.5 \%$ & NT \\
6 IDDM vs NC & $-22.0 \%$ & $-41.7 \%$ & $-30.8 \%$ \\
7 IDDM vs NC & $-10.8 \%$ & $-17.6 \%$ & $-12.4 \%$ \\
8 IDDM vs NC & $39.6 \%$ & $22.3 \%$ & $38.0 \%$ \\
9 IDDM vs NC & $18.1 \%$ & $6.7 \%$ & $12.1 \%$ \\
10 IDDM vs NC & NT & $32.1 \%$ & $17.3 \%$ \\
11 IDDm vs NC & NT & $21.4 \%$ & $29.1 \%$ \\
12 IDDM vs NC & NT & $12.3 \%$ & $27.4 \%$ \\
& & &
\end{tabular}

$N T$, not tested. The percentage difference was calculated by the difference of mean antigen density between the IDDM patient and the matched control divided by mean antigen density of the matched control $\times 100$. A minus difference means that the IDDM patient has decreased MHC class I molecule expression compared with the matched control. 
of TAP-1 activity by examining constitutive and upregulated level of TAP-1 mRNA in NOD mice and control mice. They observed no reduction in resting or cytokine- and LPS-activated TAP-1 levels in macrophages from NOD mice compared with C57BL/KsJ mice (11). Consistent with normal regulation of the TAP gene, they observed normal levels of MHC class I molecule expression on the cell surface of freshly isolated splenic lymphocytes from prediabetic NOD/Lt mice (18). Wicker et al. reported that MHC class I molecule expression on $\mathrm{T}$ cells from NOD mice is slightly lower than on BALB/C T cells, but MHC class I molecule expression on B cells from 6-wk-old NOD mice is nearly identical to that on BALB/C B cells. By 16 wk of age, however, the $B$ cells from NOD mice exhibited $40 \%$ more MHC class I molecule expression than B cells from 6-wk-old NOD mice (12). More recently, Pearce et al. reported that $\mathrm{MHC}$ class I molecule expression was slightly but significantly lower on NOD lymphocytes than on BALB/C $T$ cells, but this difference was caused by the smaller size of the NOD splenic lymphocytes, suggesting that MHC class I density on the surface of splenic lymphocytes was the same between the two strains. They also reported that there was no difference in the resting levels of TAP-1 mRNA comparing NOD mice and control mice, and no difference in TAP-1 or TAP-2 mRNA when comparing diabetic and nondiabetic NOD mice. They concluded that constitutive TAP activity and class I expression are normal in female NOD mice, irrespective of age or diabetic status (13).

We were especially interested in studying MHC class I molecule expression in IDDM because of the potential possibility initially reported by Faustman et al. that decreased MHC class I molecule expression differentiates progressors from nonprogressors to IDDM (8-10). In contrast to the reports by Faustman et al., we find no consistent decrease in MHC class I molecule expression on lymphocytes or monocytes from patients with IDDM. In addition, there is no size difference of lymphocytes or monocytes between IDDM patients and normal controls.

If in fact measurable levels of MHC class I molecule expression were lower in IDDM patients, this could be the result of a number of distinct causes that are divisible into genetic and acquired types. Faustman et al. appear to favor the idea that a genetic defect in the TAP genes results in low expression of conformational-dependent MHC class I molecules. The limited nature of the allelic difference in the TAP genes argues against this possibility. Other genetic explanations are possible; different MHC class I alleles have been shown to differ subtly in the amount of antigen they produce (19). Since IDDM patients tend to be of certain class I genotypes (e.g., B8, $\mathrm{B} 18)$, if one or more of the genotypes are low expressors, this could account for the reported differences between IDDM subjects and normal controls. The population of subjects in our study is somewhat different from that of Faustman et al. We specifically studied IDDM patients, including both recent onset and long duration, whereas Faustman et al. studied longduration IDDM patients as well as high risk relatives of IDDM patients and diabetic vs. nondiabetic twins $(8,10)$. If our IDDM patients represented a population with different MHC class I genotypes from those of Faustman et al. and MHC class I molecule expression was predominately controlled by class I genotypes, this might help explain our apparently discrepant results. There is no reason to suspect such a difference. Numerous acquired differences, such as degree of hyperglycemia, could result in lower MHC class I molecule expression. Alternatively, since B lymphocytes generally bear more surface MHC class I molecules than T lymphocytes, if IDDM patients had a higher T/B ratio than normals, MHC class I expression on lymphocytes would be found to be decreased in IDDM patients. Such acquired differences might well be expected to be highly variable in different groups of IDDM patients.

Since we found no consistent difference in MHC class I molecule expression on lymphocytes from IDDM patients, we wondered whether the degree of variability reflects the biological variation of MHC class I expression in normal controls. To answer this question, we studied 10 pairs of age- and sexmatched normal controls. Using the $\overline{\mathrm{X}} \pm 2 \mathrm{SD}$ of mean antigen density as the criterion to define MHC class I molecule expression in IDDM patients as normal, decreased, and increased, we found that $70 \%$ of IDDM patients had normal and $15 \%$ of IDDM patients had either decreased or increased MHC class I molecule expression on lymphocytes. If we had studied more normal controls, the normal range would probably have been greater, and consequently more IDDM patients would probably have been considered normal. All IDDM patients showed normal MHC class I molecule expression on monocytes. Therefore, the MHC class I molecule expression on lymphocytes from IDDM patients observed in this study is largely within the expected biological variation of MHC class I molecule expression observed in the normal controls.

Several technical points regarding the measurement of MHC class I molecule expression by flow cytometry are important to consider. First, since there is considerable variation seen in the same sample analyzed on different days because of the analysis day effect on flow cytometry, we studied the individual IDDM patient and his or her age- and sex-matched control on the same day. This allows direct comparison of mean antigen density of MHC class I molecule expression of the IDDM patient and control. Second, peptide binding is required for efficient assembly, intracellular transport, and maintaining stability of MHC class I molecules on the cell surface, and nonpeptide bound (empty) MHC class I molecules are more rapidly degraded. Exposing cells to low temperature (less than body temperature) and high serum concentration in vitro will decrease the degradation rate of empty MHC class I molecules and result in partial correction of the apparent defective pattern of MHC class I molecule expression $(9,16,20$, 21). Faustman et al. reported that exposure of NOD splenocytes to $10 \%$ serum-containing medium at room temperature for 3-5 h before flow cytometry analysis partially corrects the defective pattern of MHC class I expression $(9,16)$. To prevent low temperature and high serum concentration from correcting decreased MHC class I molecule expression in vitro, we requested IDDM patients to come to our laboratory for blood withdrawal, performed the separation of PBLs immediately after blood withdrawal, exposing cells only to low serum-containing media ( $2 \% \mathrm{FBS}$ ) at room temperature during the staining procedure, as suggested by Dr Faustman, and performed flow cytometry analysis immediately after staining. All samples were measured by a FACScan ${ }^{\circledR}$ within $2-3 \mathrm{~h}$ of blood withdrawal. All procedures and experimental conditions exactly followed Dr. Faustman's protocol for measuring MHC class I molecules by flow cytometry. Third, we studied all our subjects with mAb W6/32, kindly provided by Dr. Faustman. The concentration of $\mathrm{W} 6 / 32$ we used represents an excess of $50 \%$ above the saturation point to maximize the measurement 
of conformational-dependent (peptide-occupied) MHC class I molecules, as suggested by Dr. Faustman. We also studied a subset of our subjects with other conformational-dependent MHC class I mAbs including HIDE and P10.1 as well as W6/ 32. We found consistent results of MHC class I molecule expression in each individual pair. There was no consistent decreased expression of MHC class I molecule on PBLs using any of these three conformational-dependent MHC class I antibodies. Fourth, we tested two different anticoagulants, heparin and acid citrate dextrose, to determine the potential effect on the result. We found that the two different anticoagulants did not affect the measurement of MHC class I molecule expression (data not shown). Fifth, Faustman et al. reported that in IDDM patients, decreased MHC class I molecule expression showed more dramatically on monocytes than on lymphocytes (10). We set up two gates on flow cytometry by size to distinguish lymphocytes from monocytes and measured MHC class I molecule expression on the two cell populations, respectively. The setting of the lymphocyte and monocyte gates was demonstrated to be $>95 \%$ efficient using specific cell markers. We found that similar to lymphocytes, there was no consistent decreased MHC class I molecule expression on monocytes from IDDM patients. Sixth, we had set up positive and negative controls in our study. The cell line with known defective class I molecule expression showed dramatically decreased MHC class I molecule expression compared with the cell lines with known normal expression of MHC class I molecules.

In conclusion, we find in this study that MHC class I molecule expression is normal on PBLs from patients with IDDM.

\section{Acknowledgments}

We would like to thank Dr. Faustman for providing mAb W6/32, opening her laboratory to us, working with us to establish this methodology, and sharing with us the technical concerns regarding measurement of MHC class I molecule expression by flow cytometry. We are grateful to Bristol-Myers Squibb Pharmaceutical Research Institute for providing mAbs HIDE, P10.1, and experimental equipment for performing this study. We also thank the administration staff of Diabetes Endocrinology Research Center for assistance in preparation of the manuscript.

This work was supported in part by a grant from the Juvenile Diabetes Foundation, by the Medical Research Service of the Department of Veteran Affairs through a VA Merit Review grant, and by National Institutes of Health grants DK17047 and DK02456.

\section{References}

1. Bjorkman, J.P., and P. Parham. 1990. Structure, function and diversity of class I major histocompatibility complex molecules. Annu. Rev. Biochem. 59:
253-288.

2. Auffray, C., and J.L. Strominger. 1986. Molecular genetics of the human major histocompatibility. Adv. Hum. Genet. 15:197-247.

3. Deverson, E.V., I.R. Gow, W.J. Coadwell, J.J. Monaco, G.W. Butcher, and J.C. Howard. 1990. MHC class II region encoding proteins related to the multidrug resistance family of transmembrane transporters. Nature (Lond.). 348:738-741.

4. Monaco, J.J., S. Cho, and M. Attaya. 1990. Transport protein genes in the murine MHC: possible implications for antigen processing. Science (Wash. DC). 250:1723-1726.

5. Spies, T., M. Bresnahan, S. Bahrarn, D. Arnold, G. Blanck, E. Mellins, D. Pious, and R. DeMars. 1990. A gene in the human major histocompatibility complex class II region controlling the class I antigen presentation pathway. Nature (Lond.). 348:744-747.

6. Trowsdale, J., I. Hanson, I. Mockridge, S. Beck, A. Townsend, and A. Kelly. 1990. Sequences encoded in the class II region of the MHC related to the ABC superfamily of transporters. Nature (Lond.). 348:741-744.

7. Neefjes, J.J., F. Momburg, and G.J. Hammerling. 1993. Selective and ATP-dependent translocation of peptides by the MHC-encoded transporter. Science (Wash. DC). 261:769-771.

8. Faustman, D., X. Li, H.Y. Lin, Y. Fu, G. Eisenbarth, J. Avruch, and J. Guo. 1991. Linkage of faulty major histocompatibility complex class I to autoimmune diabetes. Science (Wash. DC). 254:1756-1761.

9. Faustman, D., X. Li, H.Y. Lin, R. Huang, and J. Guo. 1992. Expression of intra-MHC transporter (Ham) genes and class I antigens in diabetes-susceptible NOD mice-Technical Comments. Science (Wash. DC). 256:1830-1831.

10. Fu, Y., D.M. Nathan, F. Li, X. Li, and D.L. Faustman. 1993. Defective major histocompatibility complex class I expression on lymphoid cells in autoimmunity. J. Clin. Invest. 91:2301-2307.

11. Gaskins, H.R., J.J. Monaco, and E.H. Leiter. 1992. Expression of intraMHC transporter (Ham) genes and class I antigens in diabetes-susceptible NOD mice-Technical Comments. Science (Wash. DC). 256:1826-1828.

12. Wicker, L.S., P.L. Podolin, P. Fischer, A. Sirotina, R.C. Boltz, Jr., and L.B. Peterson. 1992. Expression of intra-MHC transporter (Ham) genes and class I antigens in diabetes-susceptible NOD mice-Technical Comments. Science (Wash. DC). 256:1828-1830.

13. Pearce, R.B., L. Trigler, E.K. Svaasand, H.-M. Chen, and C.M. Peterson. 1995. Levels of Tap-1 and Tap-2 mRNA and expression of Kd and Db on splenic lymphocytes are normal in NOD mice. Diabetes. 44:572-579.

14. Gladstone, P., P. Antonelli, and J.A. Hansen, 1984. (Spatial localization of allospecific HLA class I epitopes by antibody blocking studies (original contribution). In Histocompatibility Testing. E.D. Albert, M.P. Baur, and W.R. Mayr, editors. Springer Verlag, New York. 75-76.

15. Fling, S.P., B. Arp, and D. Pious. 1994. HLA-DMA and -DMB genes are both required for MHC class II/peptide complex formation in antigen-presenting cells. Nature (Lond.). 368:554-558.

16. Li, F., J. Guo, Y. Fu, G. Yan, and D. Faustman. 1994. Abnormal class I assembly and peptide presentation in the nonobese diabetic mouse. Proc. Natl. Acad. Sci. USA. 91:11128-11132.

17. Huang, R., J. Guo, X. Li, and D.L. Faustman. 1995. Elimination of selfpeptide major histocompatibility complex class I reactivity in NOD and $\beta_{2}$-microglobulin-negative mice. Diabetes. 44:1114-1120.

18. Leiter, E.H., G.J. Christianson, D.V. Serreze, A.T. Ting, and S.M. Worthen. 1989. MHC antigen induction by interferon gamma on cultured mouse pancreatic beta cells and macrophages. J. Exp. Med. 170:1243-1262.

19. Gladstone, P., L. Fueresz, and D. Pious. 1982. Gene dosage and gene expression in the HLA region: evidence from deletion variants. Proc. Natl. Acad. Sci. USA. 79:1235-1239.

20. Rock, K.L., C. Gramm, and B. Benacerraf. 1991. Low temperature and peptides favor the formation of class I heterodimers on RMA-S cells at the cell surface. Proc. Natl. Acad. Sci. USA. 88:4200-4204.

21. Ljunggren, H.-G., N.J. Stam, C. Ohlen, J.J. Neefjes, P. Hoglund, M.-T. Heemels, J. Bastin, T.N.M. Schumacher, A. Townsend, K. Karre, and H.L. Ploegh. 1990. Empty MHC class I molecules come out in the cold. Nature (Lond.). 346:476-480. 